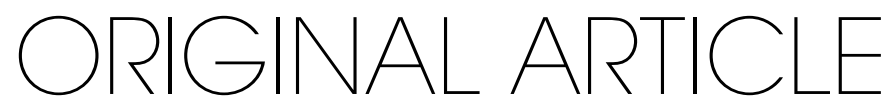

\title{
Genome-wide DNA methylation pattern in visceral adipose tissue differentiates insulin-resistant from insulin-sensitive obese subjects
}

\author{
A. B. CRUJEIRAS ${ }^{1}$, A. DIAZ-LAGARES ${ }^{1}$, J. M. MORENO-NAVARRETE, J. SANDOVAL, D. HERVAS, \\ A. GOMEZ, W. RICART, F. F. CASANUEVA, M. ESTELLER, and J. M. FERNANDEZ-REAL
}

L'HOSPITALET AND BARCELONA, CATALONIA; SANTIAGO DE COMPOSTELA, MADRID AND VALENCIA, SPAIN

\begin{abstract}
Elucidating the potential mechanisms involved in the detrimental effect of excess body weight on insulin action is an important priority in counteracting obesityassociated diseases. The present study aimed to disentangle the epigenetic basis of insulin resistance by performing a genome-wide epigenetic analysis in visceral adipose tissue (VAT) from morbidly obese patients depending on the insulin sensitivity evaluated by the clamp technique. The global human methylome screening performed in VAT from 7 insulin-resistant (IR) and 5 insulin-sensitive (IS) morbidly obese patients (discovery cohort) analyzed using the Infinium HumanMethylation450 BeadChip array identified $982 \mathrm{CpG}$ sites able to perfectly separate the IR and IS samples. The identified sites represented 538 unique genes, $10 \%$ of which were diabetes-associated genes. The current work identified novel IR-related genes epigenetically regulated in VAT, such as COL9A1, COL1IA2, CD44, MUC4, ADAM2, IGF2BPI, GATA4, TETI, ZNF714, ADCY9, TBX5, and HDACM. The gene with the largest methylation fold-change and mapped by 5 differentially methylated CpG sites located in island/shore and promoter region was ZNF714. This gene presented lower methylation levels in IR than in IS patients in association with increased transcription levels, as further reflected in a validation cohort ( $n=24 ; 11$ IR and 13 IS). This study reveals, for the first time, a potential epigenetic regulation involved in the dysregulation of VAT that could predispose patients to insulin resistance and future type 2 dia-
\end{abstract}

\footnotetext{
${ }^{1}$ Both authors equally contributed to this work.

From the Cancer Epigenetics and Biology Program (PEBC), Bellvitge Biomedical Research Institute (IDIBELL), L'Hospitalet, Catalonia, Spain; Laboratory of Molecular and Cellular Endocrinology, Instituto de Investigación Sanitaria (IDIS), Complejo Hospitalario Universitario de Santiago (CHUS) and Santiago de Compostela University (USC), Santiago de Compostela, Spain; CIBER Fisiopatología de la Obesidad y la Nutrición (CIBERobn), Madrid, Spain; Cancer Epigenetics and Biology Program (PEBC), Bellvitge Biomedical Research Institute (IDIBELL), L'Hospitalet, Catalonia, Spain; Department of Diabetes, Endocrinology and Nutrition, Institut D'investigació Biomèdica De Girona (IdIBGi); CIBER Fisiopatología de la Obesidad y la Nutrición (CIBERobn), Madrid, Spain; Laboratory of Personalized Medicine, Epigenomics Unit, Medical Research Institute La Fe, Valencia, Spain; Biostatistics Unit, Medical Research Institute La Fe, Valencia, Spain; Laboratory of Molecular and Cellular Endocrinology, Instituto de Investigación Sanitaria (IDIS), Complejo Hospitalario Universitario de Santiago (CHUS) and Santiago de Compostela University (USC), Santiago de Compostela, Spain; CIBER Fisiopatología de la Obesidad y la
}

\footnotetext{
Nutrición (CIBERobn), Madrid, Spain; Cancer Epigenetics and Biology Program (PEBC), Bellvitge Biomedical Research Institute (IDIBELL), L'Hospitalet, Catalonia, Spain; Institucio Catalana de Recerca i Estudis Avançats (ICREA); Passeig de Lluís Companys, 23, Barcelona, Catalonia, Spain.

Submitted for publication February 19, 2016; revision submitted June 30, 2016; accepted for publication July 6, 2016.

Reprint requests: Dr. Ana B. Crujeiras, Molecular and Cellular Endocrinology Area (Lab. 2), Instituto de Investigación Sanitaria (IDIS), Complejo Hospitalario Universitario de Santiago (CHUS), C/ Choupana, s/n, 15706 Santiago de Compostela, Spain; e-mail: anabelencrujeiras@hotmail.com or Dr. José Manuel Fernandez-Real, Section of Diabetes, Endocrinology and Nutrition, Hospital of Girona "Dr Josep Trueta", Carretera de França s/n, 17007, Girona, Spain; e-mail: jmfreal@idibgi.org.

$1931-5244 / \$$ - see front matter

(C) 2016 Elsevier Inc. All rights reserved.

http://dx.doi.org/10.1016/j.trs1.2016.07.002
} 


\section{betes in morbid obesity, providing a potential therapeutic target and biomarkers for} counteracting this process. (Translational Research 2016; $1: 1-12$ )

Abbreviations: $\mathrm{VAT}=$ visceral adipose tissue; $I \mathrm{R}=$ insulin resistant; $I S=$ insulin sensitive; $\mathrm{DMCpGs}=$ differentially methylated CpG sites; $\mathrm{GO}=$ gene ontology; HDPP = Human Diabetes Proteome Project; T2D = type 2 diabetes

\section{AT A GLANCE COMMENTARY}

\section{Crujeiras $A B$, et al.}

\section{Background}

Because epigenetic modifications are dynamic, reversible, and change in response to several environmental factors, epigenetic markers related to insulin resistance may represent therapeutic targets for the prevention of future type 2 diabetes onset in morbidly obese patients. The present study evaluates the epigenetic basis of insulin resistance by performing a genome-wide epigenetic analysis in visceral adipose tissue from morbidly obese patients depending on the insulin sensitivity.

\section{Translational Significance}

The epigenome-wide analysis performed in this study identified a number of genes that could comprise an epigenetic signature of insulin resistance-related adipose tissue pathogenesis, providing for the first time new and valuable DNA methylation biomarkers of visceral adipose tissue pathogenesis that are associated with insulin resistance. Therefore, the observations of the current work are of foremost relevance as they provide tools for additional personalized treatment for prevention of type 2 diabetes.

\section{INTRODUCTION}

Insulin resistance refers to the inability of insulin to regulate systemic glucose metabolism. This condition is known to play a major role in the deleterious metabolic features associated with excess body weight. ${ }^{1}$ As an underlying pathophysiological factor linked to the metabolic syndrome, ${ }^{2}$ insulin resistance increases the risk of all causes of cancer and cardiovascular disease mortality. ${ }^{3,4}$ Among the mediators of insulin resistance associated with obesity, visceral adipose tissue (VAT) appears to play a relevant role in the development and maintenance of this disturbance. The amount of VAT has been shown to be the best predictor of insulin resistance measured by the clamp technique, ${ }^{5-7}$ and it showed the strongest correlation with HOMA-IR according to a recent meta-analysis. ${ }^{8}$ This is because the dysfunctional visceral adipose tissue associated with obesity secretes several factors that play relevant roles in obesity and obesity-related comorbidities. ${ }^{9}$ However, the specific mechanism by which VAT becomes dysfunctional in promoting obesity-related complications, such as insulin resistance, must be fully disclosed.

Insulin resistance is known to be modulated by both genetic and environmental influences. ${ }^{10}$ The interaction between these factors in the disease development can be mediated by epigenetic modifications. Epigenetic markers might explain the link between lifestyle and the risk of disease and have been proposed to be sensitive biomarkers and potential therapeutic targets for disease management. ${ }^{11}$ Among epigenetic mechanisms, DNA methylation is the best studied epigenetic regulatory mechanism. DNA methylation has been proposed as a next-generation biomarker with great diagnostic and prognostic promise for clinicians. ${ }^{12}$ In this context, previous studies have explored epigenetic involvement in obesity. ${ }^{13}$ Moreover, the methylome of human pancreatic islets associated with type 2 diabetes (T2D) has been characterized, demonstrating that altered DNA methylation in human islets contributes to perturbed hormone secretion and the pathogenesis of T2D. ${ }^{14}$ Furthermore, DNA methylation levels in adipose tissue have been related to alterations in glucose metabolism. ${ }^{15}$ Differences in the methylation levels of VAT have also been identified by comparing patients with and without metabolic syndrome through a genome-wide differential methylation analysis. ${ }^{16}$ However, the methylome of VAT has not been explored until now in insulin-resistant (IR) patients classified by the clamp technique, the gold-standard method for evaluating insulin sensitivity. ${ }^{17}$

The present study aimed to disentangle the epigenetic basis of insulin resistance by performing a genomewide epigenetic analysis in VAT from morbidly obese patients depending on the insulin sensitivity evaluated by the clamp technique.

\section{SUBJECTS AND METHODS}

Study participants. A group of morbidly obese Caucasian patients $(\mathrm{n}=36)$ with different degrees of insulin 
sensitivity were included in this study. We first evaluated a discovery cohort $(\mathrm{n}=5$ insulin-sensitive (IS) and $\mathrm{n}=7$ IR morbidly obese participants). An extended validation cohort composed of 24 morbidly obese Caucasian patients with different degrees of insulin sensitivity was analyzed $(\mathrm{n}=13$ IS and $\mathrm{n}=11 \mathrm{IR})$. All participants were recruited at the Endocrinology Service of the University Hospital of Dr. Josep Trueta (Girona, Spain). All subjects confirmed that their body weight had been stable for $\geq 3$ months before the study. Written informed consent to participate in the trial was obtained before the beginning of the study, in agreement with the Declaration of Helsinki, and the study was performed following the national and European Union guidelines. The protocol of this study was approved by the Hospital Ethics Committee.

VAT samples were obtained during elective surgical procedures (cholecystectomy, surgery for abdominal hernia and gastric bypass surgery), washed, and immediately flash-frozen in liquid nitrogen before being stored at $-80^{\circ} \mathrm{C}$. Anthropometric, biochemical determinations, and an euglycemic-hyperinsulinemic clamp for insulin action measurement were implemented as aforemen- tioned. ${ }^{17}$ Insulin resistance was defined by the M-values cutoff <4.7. ${ }^{18,19}$ DNA samples were isolated from $200 \mathrm{mg}$ of VAT. The anthropometric and clinical characteristics of these subjects are shown in Table I.

DNA methylation and gene expression analysis. Microarray-based DNA methylation analysis was conducted with the Infinium Human Methylation 450 BeadChip (450K array; Illumina) following the Illumina Infinium HD methylation protocol (Supplementary Materials \& methods). DNA quality checks, bisulfite modification, hybridization, data normalization, statistical filtering, and $\beta$ value calculations to assess the cytosine methylation states were performed as described elsewhere. ${ }^{20,21}$

Pyrosequencing was used to assess selected markers as aforementioned. ${ }^{22}$ Pyrosequencing reactions and methylation quantification were performed in a PyroMark Q96 ID System (Qiagen) using appropriate reagents and protocols recommended by the manufacturer (details and primer sequences are available in the Supplementary Methods). Gene expression was assessed by real-time PCR using TaqMan technology suitable for relative gene expression quantification in a LightCycler 480 Real-Time PCR System (Roche

Table I. Anthropometric and clinical parameters of study subjects from discovery and validation cohort

\begin{tabular}{|c|c|c|c|}
\hline & IS & IR & $P$-value \\
\hline \multicolumn{4}{|l|}{ Discovery cohort } \\
\hline $\mathrm{N}$ & 5 & 7 & \\
\hline Gender (men/women) & $1 / 4$ & $1 / 6$ & \\
\hline Age $(y)$ & $53.2 \pm 10.3$ & $46.5 \pm 9.3$ & 0.2 \\
\hline $\mathrm{BMI}\left(\mathrm{kg} / \mathrm{m}^{2}\right)$ & $39.4 \pm 7.8$ & $44.9 \pm 5.04$ & 0.1 \\
\hline Waist $(\mathrm{cm})$ & $111.4 \pm 13.7$ & $130.1 \pm 7.3$ & 0.01 \\
\hline Fasting glucose (mg/dl) & $93 \pm 14.9$ & $103.2 \pm 19.8$ & 0.3 \\
\hline $\mathrm{HbA}_{1 \mathrm{c}}(\%)$ & $5.2 \pm 0.4$ & $6.1 \pm 0.7$ & 0.04 \\
\hline Euglycemic clamp (mg/kg · min) & $7.4 \pm 1.6$ & $3.4 \pm 0.8$ & $<0.0001$ \\
\hline Total-cholesterol (mg/dl) & $202.6 \pm 27.2$ & $194.7 \pm 45.6$ & 0.7 \\
\hline LDL-cholesterol (mg/dl) & $128 \pm 25.3$ & $123.5 \pm 36.4$ & 0.8 \\
\hline HDL-Cholesterol (mg/dl) & $57 \pm 8.8$ & $43.8 \pm 9.7$ & 0.03 \\
\hline Triglycerides (mg/dl) & $68(57-128)$ & $136(70-200)$ & 0.2 \\
\hline C-reactive protein (mg/dl) & $0.54(0.28-0.76)$ & $0.73(0.24-1.10)$ & 0.3 \\
\hline \multicolumn{4}{|l|}{ Validation cohort } \\
\hline $\mathrm{N}$ & 13 & 11 & \\
\hline Gender (men/women) & $1 / 12$ & $1 / 10$ & \\
\hline Age $(y)$ & $45.3 \pm 11.4$ & $48.8 \pm 6.8$ & 0.4 \\
\hline BMI $\left(\mathrm{kg} / \mathrm{m}^{2}\right)$ & $45.2 \pm 6.9$ & $45.3 \pm 6.6$ & 0.9 \\
\hline Waist $(\mathrm{cm})$ & $120.3 \pm 12.2$ & $124.4 \pm 10.3$ & 0.4 \\
\hline Fasting glucose (mg/dl) & $96.4 \pm 24.1$ & $95.2 \pm 7.2$ & 0.8 \\
\hline $\mathrm{HbA}_{1 \mathrm{c}}(\%)$ & $5.57 \pm 0.46$ & $5.73 \pm 0.31$ & 0.3 \\
\hline Euglycemic clamp $(\mathrm{mg} / \mathrm{kg} \cdot \mathrm{min})$ & $6.44 \pm 1.4$ & $2.51 \pm 1.2$ & $<0.0001$ \\
\hline Total-cholesterol (mg/dl) & $179.4 \pm 36.5$ & $208.1 \pm 34.5$ & 0.07 \\
\hline LDL-cholesterol (mg/dl) & $114.5 \pm 29.8$ & $130.7 \pm 36.1$ & 0.2 \\
\hline HDL-cholesterol (mg/dl) & $47.2 \pm 6.3$ & $50.5 \pm 20.1$ & 0.5 \\
\hline Triglycerides (mg/dl) & $82(72-95)$ & $139(117.7-159.5)$ & 0.003 \\
\hline C-reactive protein (mg/dl) & $0.8(0.45-1.31)$ & $0.95(0.65-1.38)$ & 0.9 \\
\hline
\end{tabular}

Bold values indicate statistically significant data $(P<0.05)$.

Abbreviations: $I S$, insulin sensitive patients; $I R$, insulin resistant patients; $B M I$, body mass index. 
Diagnostics SL, Barcelona, Spain). The commercially available and prevalidated TaqMan primer/probe sets used were cyclophilin A (human peptidylprolyl isomerase A, 4333763, endogenous control) and zinc finger protein 714 (ZNF714, Hs02743732_s1) from Life Technologies S.A., Madrid, Spain. Fold changes relative to an endogenous control (PPIA) were determined by calculating $2^{-\Delta \mathrm{Ct} \text {. }}$

Statistical analyses. Anthropometric and clinical characteristics of individuals are expressed as mean \pm standard deviation. Differences in these data between IR and IS patients were tested by unpaired Student $t$ test. The methylation level of each cytosine was expressed as a $\beta$ value calculated as the fluorescence intensity ratio of the methylated to the unmethylated versions of the probes. The $\beta$ values ranged between 0 (unmethylated) and 1 (completely methylated) according to a combination of the $\mathrm{Cy} 3$ and Cy5 fluorescence intensities. Color balance adjustment and quantile normalization were performed to normalize the samples between the 2 color channels. $\beta$ values with detection $P$-values $>0.01$ were considered to fall below the minimum intensity and threshold, and these values were consequently removed from further analysis. Approximately $96 \%$ of the $\mathrm{CpG}$ islands were covered, along with regions proximal to the $\mathrm{CpG}$ islands ("CpG shores") and the more distal $\mathrm{CpG}$ shelves. In addition, the probes that were localized to the sex chromosomes and those considered single nucleotide polymorphisms were filtered out.

To identify consistent patterns of differentially methylated $\mathrm{CpG}$ sites (DMCpGs) between the IR and IS VAT samples, nonparametric Wilcoxon rank-sum tests were performed. $P$-values were adjusted for multiple comparisons using the false discovery rate procedure of Benjamini and Hochberg. In this analysis, a false discovery rate below 5\% ( $q$ value) was considered statistically significant. However, given the sample size, we selected the raw $P$-values of $<0.05$ as a less stringent cutoff for differential methylation than $q$ values. In addition, we applied a threshold for the significant sites based on the mean differences between groups with a minimum $\beta$ value change of \pm 0.05 . The $P$-values were represented in a Manhattan plot $(-\log 10$ of the $P$-value by genomic location). Hierarchical cluster analysis of the significant $\mathrm{CpGs}$ was performed using the heatmap function. The overall distribution of significant $\mathrm{CpG}$ sites compared with all analyzed sites on the Infinium HumanMethylation 450 BeadChip was analyzed using a chi-square test. All of the aforementioned statistical analyses were performed using $\mathrm{R}$ software (version 3.2.0).
To estimate the enrichment in biological processes, a hypergeometric test was performed on the biological processes defined by gene ontology (GO). ${ }^{23}$ This analysis detected the significant over-representation of GO terms in one of the sets (ie, list of selected genes) with respect to the other for the entire genome. GO terms with an adjusted $P$-value of $<.05$ were considered significant.

Differences in DNA methylation levels detected by pyrosequencing and expression of selected genes between groups were assessed by the nonparametric Mann-Whitney U test using the SPSS version 17.0 software (SPSS Inc, Chicago, Ill) for Windows XP (Microsoft, Redmond, Wash). $P$-values of $\leq 0.05$ were considered statistically significant.

\section{RESULTS}

Clinical characteristics of subjects with different degrees of insulin sensitivity. Thirty-six morbid obese patients were included in this study. The IS and IR individuals were matched for age, gender, and body mass index in both the discovery and the validation cohorts (Table I). Statistically significant changes were observed in parameters associated with insulin resistance, such as waist circumference, $\mathrm{HbA}_{1 \mathrm{c}}$, and lipid profile, in addition to differences in the M-clamp value, as expected by design (Table I).

Differential DNA methylation in VAT from IR vs IS patients. Direct comparison of the average of methylation levels of the 447,104 valid CpGs revealed relatively similar global patterns between IR and IS (Supplemental Fig S1A). The comparison of the DNA methylation levels between IR and IS obese VATs revealed 982 individual $\mathrm{CpG}$ sites that exhibit differential DNA methylation $\geq 5 \%(P<.05)$ between both groups (Supplemental Table S1). The change in DNA methylation of individual $\mathrm{CpG}$ sites with a significant difference between IR and IS $(P<.05)$ ranged from -0.38 to 0.77 (Supplemental Fig S1B), and most of the differentially methylated $\mathrm{CpG}$ sites (DMCpGs) presented absolute differences between $5 \%$ and $10 \%$. No differences were observed in the average DNA methylation levels of the 982 individual DMCpG sites (Supplemental Fig S1C). A Manhattan and a correlation plot between IR and IS patients are shown in Supplemental Figures S1D and S1E, respectively.

Genomic and chromosomal distribution of differentially methylated CpG sites in IR VAT. The 982 identified CpG sites were associated with 538 unique genes (Supplemental Table S1). The majority were located outside CpG-rich regions ( $\mathrm{CpG}$ islands), mainly in the open-sea region (Fig 1A). Moreover, the identified 
A

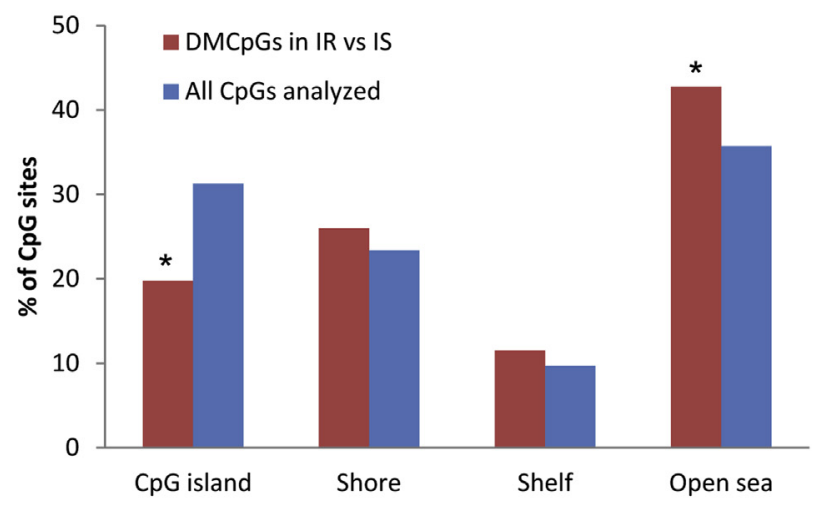

B

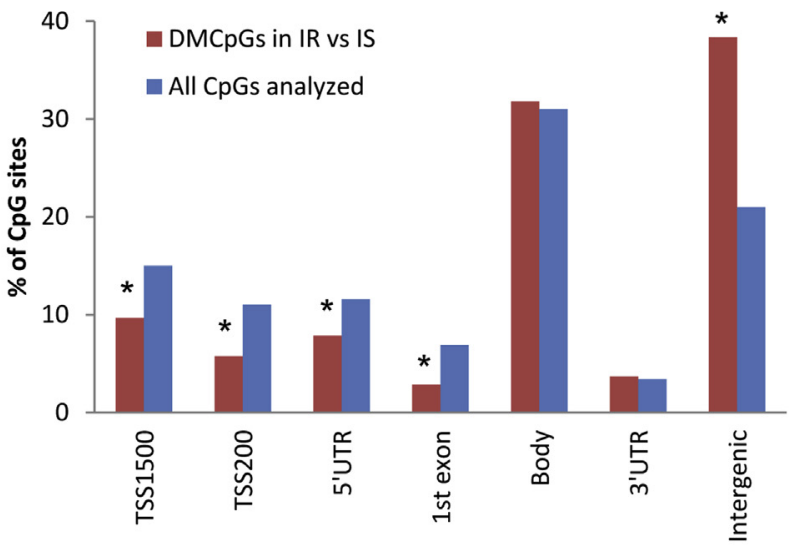

C
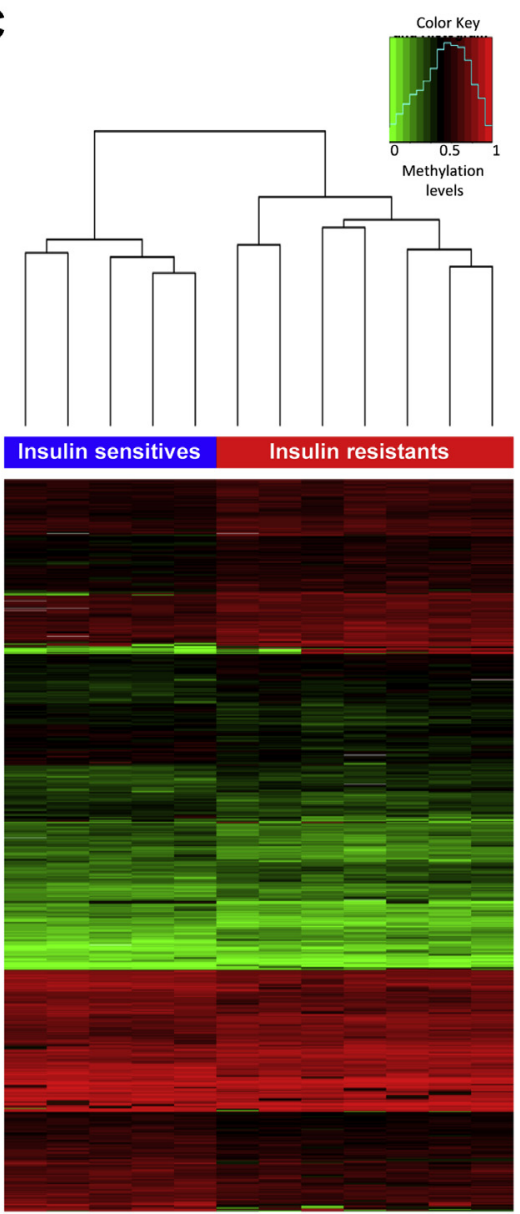

Fig 1. Characterization of the $\mathrm{CpG}$ sites that exhibit differential DNA methylation in insulin-resistant and insulinsensitive patients. (A) Genomic distribution of the differentially methylated $\mathrm{CpG}$ sites (DMCpGs) compared with all the $\mathrm{CpGs}$ in the $450 \mathrm{~K}$ array and in relation to their respective locations in the broader $\mathrm{CpG}$ context and (B) gene region. $\mathrm{CpG}$ islands, areas of the genome with a high density of cytosine-phosphate-guanine $(\mathrm{CpG})$ dinucleotides; shores, areas of the genome up to $2 \mathrm{~Kb}$ from $\mathrm{CpG}$ islands; shelves, $2-4 \mathrm{~Kb}$ from $\mathrm{CpG}$ islands; open sea, $>4 \mathrm{~Kb}$ from CpG islands. (C) Supervised clustering of the $\mathrm{CpGs}$ that were found to be differentially methylated between insulin-resistant and insulin-sensitive samples. *Denotes differences statistically significant $(P<0.05)$.

CpG sites with altered levels of DNA methylation between IR and IS were enriched within the intergenic regions (Fig 1B). The $\mathrm{CpG}$ sites with decreased methylation levels in IR with respect to IS VAT were located in $\mathrm{CpG}$ islands and shores, whereas those with increased methylation levels were located in the opensea region (Supplemental Fig S1F). The distribution of gain and diminution of methylation in IR with respect to that observed in IS samples was similar regarding the respective location relative to genes (Supplemental Fig S1G). With respect to the chromosomic distribution of individual DMCpGs in IR compared with IS, those DMCpGs with increased methylation levels in IR were distributed in chromosomes $1,5,6,10,11$, and 13 , whereas those DMCpGs with decreased methylation levels in IR were mainly found in chromosomes 12, 16, and 19
(Supplemental Fig S1H). Importantly, the identified $\mathrm{CpG}$ sites were able to perfectly differentiate the IR and IS samples using a hierarchical cluster approach (Fig 1C). Additional bioinformatics analysis of the differently methylated regions yielded information regarding the overlap of these regions with enhancers, DNase hypersensitive, and open chromatin regions. For that analysis, we exploited the state-of-the-art Epic Illumina manifest, which provides information of the chromosomal coordinates for this type of important gene regulatory feature. This information was determined by the ENCODE Consortium using informatics and the original $450 \mathrm{~K}$ consortia members. This Epic updated manifest from Illumina contains 912 CpGs of the 980 DMCpGs in this study. Thus, among the $912 \mathrm{CpGs}, 257 \mathrm{CpGs}$ were located in enhancers, 541 were located in chromosomal 
coordinates of the DNase hypersensitive region, and 98 were located in chromosomal coordinates of open chromatin regions. Moreover, $247 \mathrm{CpGs}$ of the 980 DMCpGs were located in promoters (Supplemental Table S1).

Biological significance of the $\mathrm{CpG}$ sites and the associated genes in IR. A GO analysis was performed to test whether certain molecular functions or biological processes were significantly associated with genes showing a difference in DNA methylation status between IR and IS. Thus, among the significantly enriched functional processes, the categories of cell adhesion, signal transduction, and regulation of transcription exhibited the largest number of genes (Fig 2A). Relevantly, most of the genes differentially methylated were significantly $(P<.001)$ related and joined with the insulin pathway (Fig 2B). Moreover, we found 56 diabetes-associated genes according to the Human Diabetes Proteome Project that were represented by DMCpGs (Supplemental Table S2), 19 of which were located in promoter and island/shore regions (Table II).

Regarding molecular functions or biological processes, among the genes associated with cell adhesion, CpG sites associated with COL9A1, COL11A2, and $C D 44$ exhibited higher methylation levels in IR than in IS VAT, whereas $\mathrm{CpG}$ sites representing MUC4 and ADAM2 showed lower levels in IR than in IS (Fig 3A). Diminished methylation levels were also observed in IR for genes involved in transcription function, such as PER3, GATA4, PRUMB, TXNIP1, and ZNF714. Moreover HOXC4, TET1, FOXD2, and $N R B F 2$ exhibited increased methylation levels in IR with respect to those in IS (Fig 3B). Including signal transduction function, the methylation levels of DMCpGs for TNFSF14 and ADCY9 were found to have diminished in IR, whereas those coded by IGF2R, CXCL12, CXCL13, FGF7, and FGF14 were found to have increased in IR with respect to IS (Fig 3C). In addition, although not statistically significant in the GO analysis, genes with metabolic function were identified by DMCpGs such as RAMP1, MUC4, SULT1B1, HOX13, TBX5, FAMBA1, HADACM, and SCG3 (Fig 3D).

A further analysis was performed by searching for those $450 \mathrm{k}$ array probes located in island/shore promoter regions with differences in absolute $\beta$ values of $\geq 0.10$ and $P$-values of $\leq 0.01$. Under these conditions, $11 \mathrm{CpG}$ sites were detected. Among those, ZNF714 was selected because it was the gene with the largest methylation fold change and was represented by 5 consecutive $\mathrm{CpGs}$ that were differentially methylated in the island/ shore promoter region (mean delta $\beta=-0.27$; $P=.010)$.
Methylation levels of ZNF714 in a validation cohort. We used pyrosequencing to evaluate further DNA methylation levels for ZNF714. Thus, the differences in the methylation levels of ZNF714 observed in the $450 \mathrm{~K}$ array (Fig 4A) were replicated by pyrosequencing in the same cohort (Fig 4B). Importantly, the ZNF714 methylation pattern was further validated by pyrosequencing in an independent cohort (validation cohort, $n=24$; Table I; Fig 4C).

DNA methylation has previously been associated with transcription repression. ${ }^{13}$ Accordingly, IR samples showed significantly $(P=.04)$ higher expression levels of the gene ZNF714 (0.0102 \pm 0.0025$)$ than IS $(0.0052 \pm 0.0005)$, and this expression was associated with the DNA methylation levels of ZNF714 (Fig 4D). These results suggest that the epigenetic regulation of this gene related to insulin sensitivity could have a relevant biologic function.

\section{DISCUSSION}

In the current work, the genome-wide DNA methylation profile of VAT from morbidly obese patients with insulin resistance was characterized, and potential DNA methylation signatures of this metabolic disorder were identified. This work demonstrates that VAT from patients with disturbances in the insulin sensitivity presents a specific DNA methylation pattern. DNA methylation was altered in $982 \mathrm{CpG}$ sites encoding 538 unique genes with differences in beta values ranging from -0.4 to 0.8 . The identified genes were associated with functions involved in cell adhesion, signal transduction, and regulation of transcription. Relevantly, most of the genes that were differentially methylated were joined with the insulin pathway. In fact, $10 \%$ of the genes encoded by the DMCpGs in IR were identified as diabetesassociated genes. Therefore, this study demonstrates that the link between the dysfunction of VAT and insulin resistance may be epigenetically regulated, providing a potential therapeutic target and biomarkers to counteract this process.

In an obese state, adipose tissue becomes dysfunctional. The tissue loses its capacity to store fatty acids and presents altered adipokine production. This condition contributes to the etiology of obesity-related metabolic complications such as insulin resistance. ${ }^{9}$ To date, whether epigenetics play a role in adipose tissue dysfunction has remained unknown.

The present study adds new and complementary information to previous studies in relation to T2D and adiposity, supporting the potential role of epigenetics in the development of insulin-sensitivity disturbances in obesity. Previous studies have highlighted the importance of epigenetic regulation as a mechanism in the pathogenesis of $\mathrm{T} 2 \mathrm{D} .^{24}$ Detailed information 
A

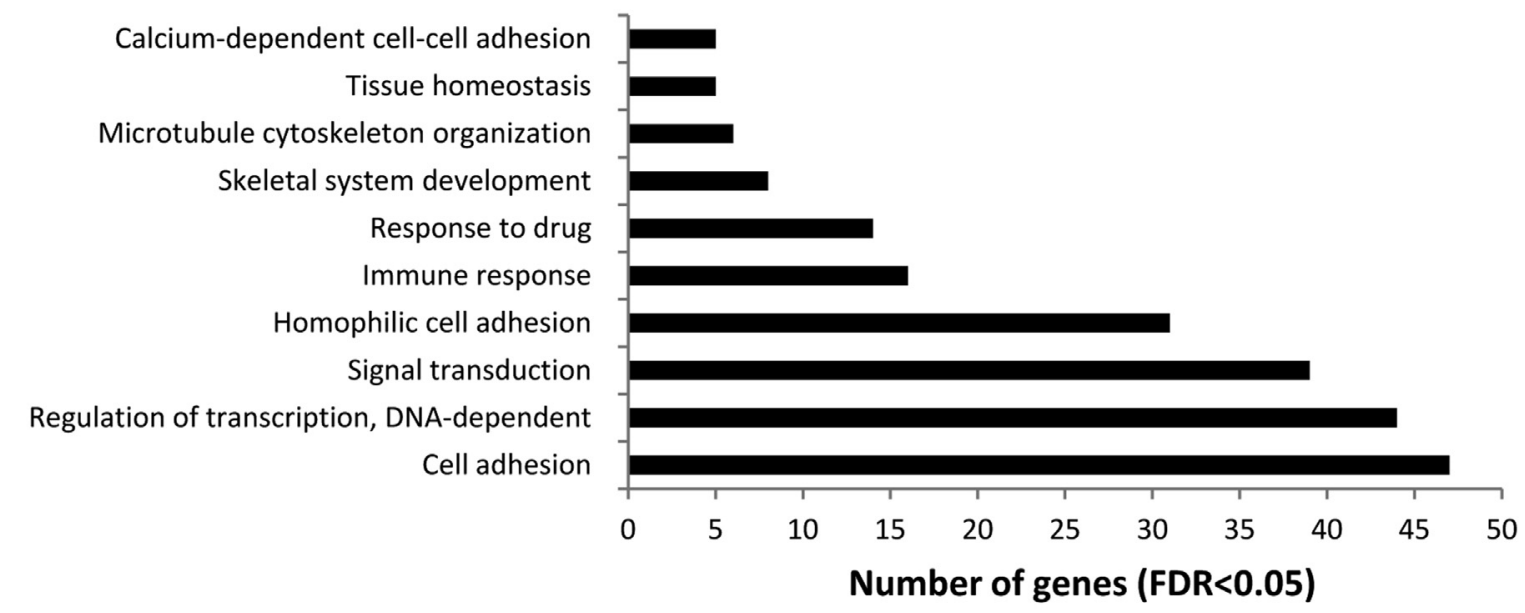

B

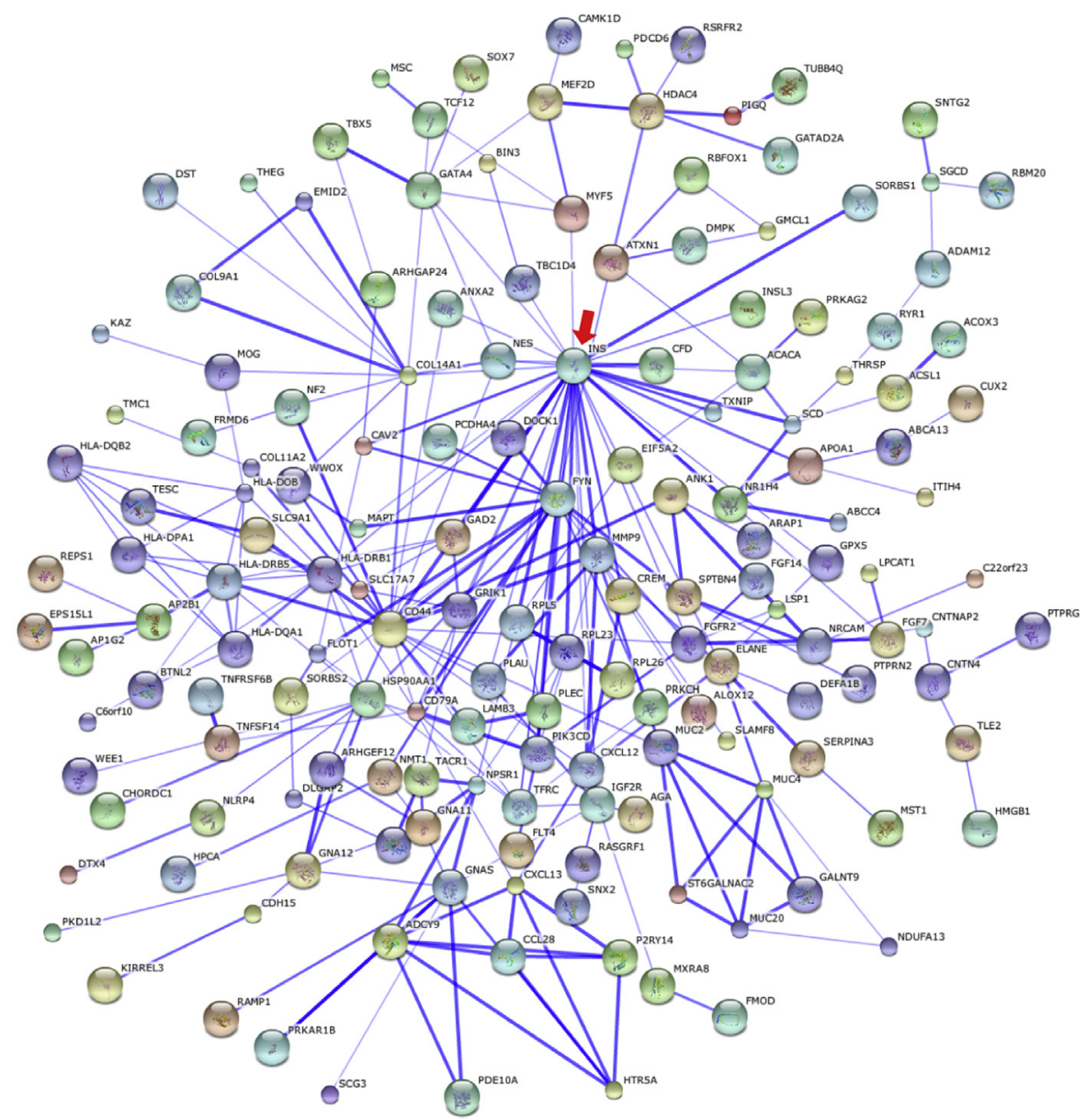

Fig 2. Biological implications of the differentially methylated $\mathrm{CpG}$ sites in insulin-resistant patients relative to insulin-sensitive patients. (A) Summary of the gene ontology (GO) analysis of the biological process categories for the differentially methylated genes represented by the DMCpG sites. (B) Gene-protein interaction networkSTRING analysis. Most of the genes regulated by methylation belong to a network significantly enriched in insulin-related pathways $(P<.001)$, according to STRING analysis. Red arrow shows insulin. (For interpretation of the references to color in this figure legend, the reader is referred to the Web version of this article.) 
Table II. The differentially DNA methylated CpGs (DMCPGs) of diabetes-associated genes according to the Human Diabetes Proteome Project (HDPP) located in promoter and island and shore and sorted by chromosome

\begin{tabular}{|c|c|c|c|c|c|c|c|c|c|c|}
\hline TargetID & CHR & Gene name & CpG context & Gene region & $\begin{array}{l}\text { IS methylation } \\
\text { levels (mean) }\end{array}$ & $\begin{array}{l}\text { IS methylation } \\
\text { levels (SD) }\end{array}$ & $\begin{array}{c}\text { IR group } \\
\text { methylation } \\
\text { levels (mean) }\end{array}$ & $\begin{array}{l}\text { IR group } \\
\text { methylation } \\
\text { levels (SD) }\end{array}$ & $\begin{array}{l}\text { Differences } \\
\quad(\text { IR-IS) }\end{array}$ & P.value \\
\hline cg22367705 & 1 & SLC9A1 & Island & TSS200 & 0.04 & 0.01 & 0.10 & 0.13 & 0.07 & 0.005 \\
\hline cg11723801 & 1 & NES & Island & 1stExon & 0.10 & 0.03 & 0.15 & 0.04 & 0.05 & 0.030 \\
\hline cg08764927 & 1 & PER3; PER3 & Island & 5'UTR; 1stExon & 0.64 & 0.04 & 0.58 & 0.05 & -0.06 & 0.048 \\
\hline cg00398048 & 4 & AGA & S_Shore & TSS1500 & 0.31 & 0.07 & 0.23 & 0.05 & -0.08 & 0.030 \\
\hline cg07858113 & 6 & IER3; FLOT1 & Island & 3'UTR; TSS1500 & 0.23 & 0.07 & 0.15 & 0.03 & -0.08 & 0.048 \\
\hline cg00917413 & 7 & CAV2; CAV2 & N_Shore & TSS1500; TSS1500 & 0.72 & 0.03 & 0.78 & 0.06 & 0.05 & 0.048 \\
\hline cg16490176 & 10 & PLAU; C10orf55; PLAU & Island & TSS200; 3'UTR; TSS200 & 0.30 & 0.02 & 0.25 & 0.03 & -0.05 & 0.010 \\
\hline cg16490176 & 10 & PLAU; C10orf55; PLAU & Island & TSS200; 3'UTR; TSS200 & 0.30 & 0.02 & 0.25 & 0.03 & -0.05 & 0.010 \\
\hline cg02114346 & 10 & PAOX; PAOX; PAOX & N_Shore & TSS1500; TSS1500; TSS1500 & 0.61 & 0.03 & 0.55 & 0.03 & -0.06 & 0.010 \\
\hline cg08133496 & 11 & EXT2; EXT2 & N_Shore & TSS200; TSS200 & 0.33 & 0.03 & 0.39 & 0.03 & 0.06 & 0.009 \\
\hline cg09558982 & 11 & APOA1 & S_Shore & TSS200 & 0.35 & 0.07 & 0.45 & 0.09 & 0.11 & 0.048 \\
\hline cg17878506 & 13 & TBC1D4 & Island & TSS1500 & 0.13 & 0.10 & 0.25 & 0.11 & 0.12 & 0.048 \\
\hline cg07470694 & 15 & ATP10A & S_Shore & TSS1500 & 0.73 & 0.07 & 0.81 & 0.03 & 0.08 & 0.030 \\
\hline cg03077331 & 17 & FN3K & Island & TSS1500 & 0.07 & 0.03 & 0.13 & 0.03 & 0.06 & 0.018 \\
\hline cg27457921 & 17 & $\begin{array}{c}\text { MAPT; MAPT; MAPT; MAPT; } \\
\text { МAPT; MAPT }\end{array}$ & S_Shore & $\begin{array}{l}\text { 5'UTR; 5'UTR; 5'UTR; } \\
\text { 5'UTR; 5'UTR; 5'UTR }\end{array}$ & 0.72 & 0.03 & 0.66 & 0.04 & -0.06 & 0.030 \\
\hline cg15104526 & 19 & INSL3 & Island & TSS200 & 0.87 & 0.03 & 0.93 & 0.04 & 0.06 & 0.030 \\
\hline cg24292351 & 19 & INSL3 & Island & TSS200 & 0.88 & 0.03 & 0.93 & 0.04 & 0.05 & 0.030 \\
\hline cg23484981 & 20 & $\begin{array}{l}\text { GNAS; GNAS; GNAS; } \\
\text { GNASAS }\end{array}$ & N_Shore & $\begin{array}{c}\text { TSS1500; TSS1500; 3'UTR; } \\
\text { TSS1500 }\end{array}$ & 0.56 & 0.18 & 0.46 & 0.02 & -0.10 & 0.018 \\
\hline cg03529184 & 20 & DEFB124; REM1 & N_Shore & TSS1500; TSS1500 & 0.52 & 0.05 & 0.59 & 0.03 & 0.07 & 0.030 \\
\hline
\end{tabular}

Abbreviations: IS, insulin sensitive patients; IR, insulin resistant patients; $S D$, standard deviation. 
A

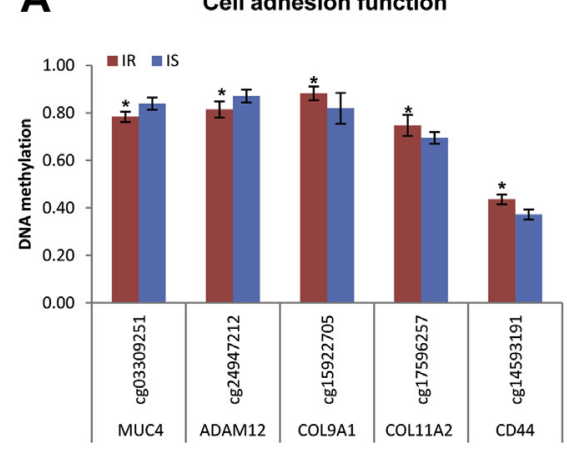

B

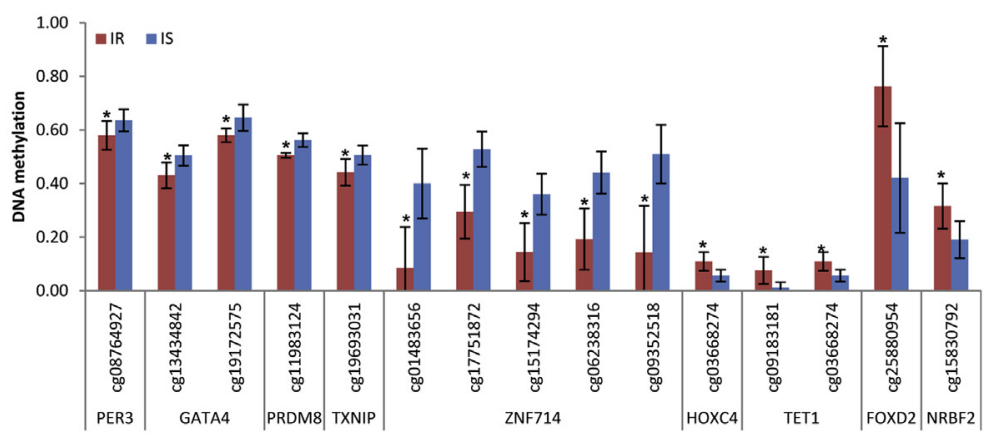

C

Signal transduction function

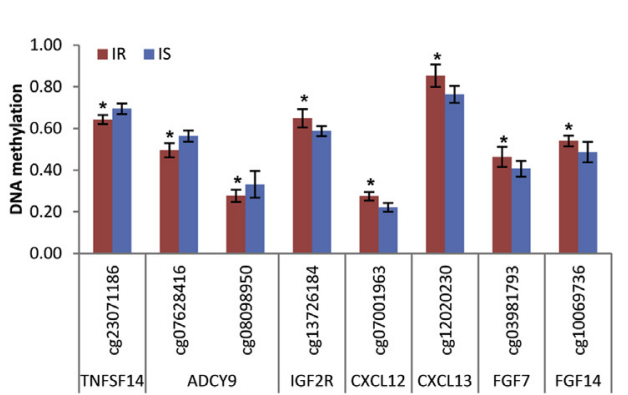

D

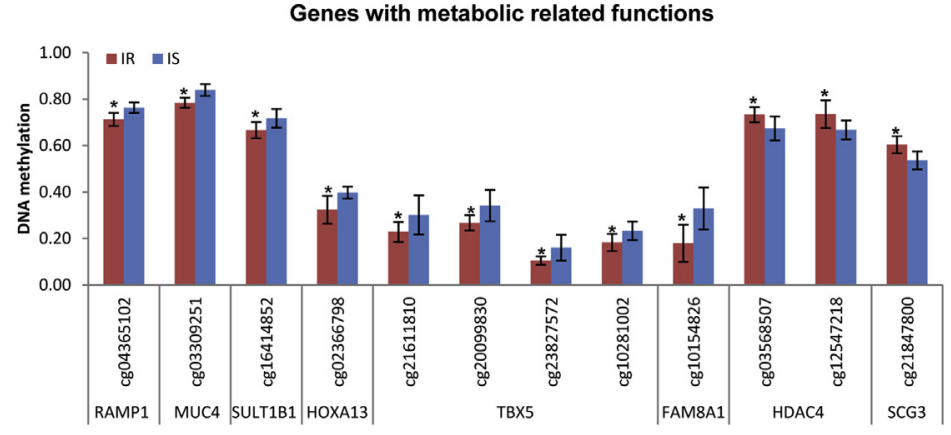

Fig 3. Genes with known functions that present differential DNA methylation in insulin-resistant and insulinsensitive patients. (A) Novel genes potentially involved in the onset of insulin resistance associated with cell-adhesion function, (B) regulation of transcription function, (C) signal transduction function, and (D) metabolic-related functions. DNA methylation values are expressed as $\beta$-values from the $450 \mathrm{~K}$ array. *Denotes differences statistically significant $(P<0.05)$.

concerning the DNA methylome in human pancreatic islets from T2D and nondiabetic patients has been provided. ${ }^{14,25}$ Genome-wide DNA methylation studies in human skeletal muscle from individuals with or without a family history of T2D have also indicated differential methylation in genes involved in insulin signaling and muscle function. ${ }^{26}$ Global methylation levels in subcutaneous adipose tissue are correlated with measures of fat distribution and glucose homeostasis. ${ }^{15}$ Moreover, differential methylation has previously been observed in VAT of obese men discordant for metabolic syndrome. ${ }^{16}$ However, to the best of our knowledge, the present study is the first to involve a DNA methylation genome-wide analysis in VAT from morbidly obese patients in relation to insulin resistance by classifying patients according to the gold-standard technique for evaluating insulin sensitivity.

The IR-related DMCpGs were distributed mainly in the intergenic and open-sea regions, in agreement with what has been previously reported in white adipose tissue $^{27,28}$ and in isolated fat cells in relation to adiposity ${ }^{29}$ and $\mathrm{T} 2 \mathrm{D}^{26}$ and metabolic syndrome. ${ }^{16}$ The mean magnitude of the absolute differences in beta values was small, in line with that observed in previous studies of adipose tissue. ${ }^{16,29-31}$ Although previous studies have reported global hypomethylation associated with $\mathrm{T} 2 \mathrm{D},{ }^{24}$ in the present study no differences were observed in the global methylation levels between IR and IS morbidly obese patients. However, the differential methylation analysis between IR and IS patients revealed genes involved in pathways associated with the function of adipose tissue, such as cell adhesion, signal transduction, and regulation of transcription. Relevantly, in agreement with the role of VAT in insulin resistance and future T2D onset, a significant number of genes mapped by the DMCpGs between IR and IS were associated with the insulin pathway and belong to the list of genes related to T2D.

Regarding the mechanism involved in the obesityrelated dysregulation of adipose tissue, several lines of evidence suggest that the remodeling of the extracellular matrix, particularly collagens, is essential for adipocyte and adipose tissue expansion, which is dysregulated in an obese state. ${ }^{32}$ In agreement with the epigenetic point of view of this proposal, because novel IR-related genes are epigenetically regulated in VAT, the current work 
A

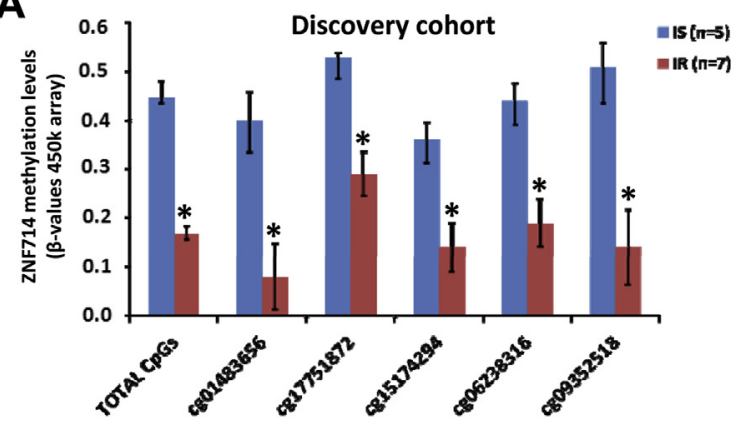

B

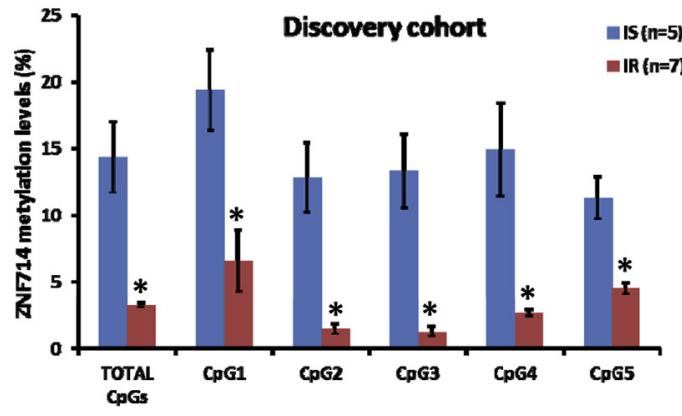

C

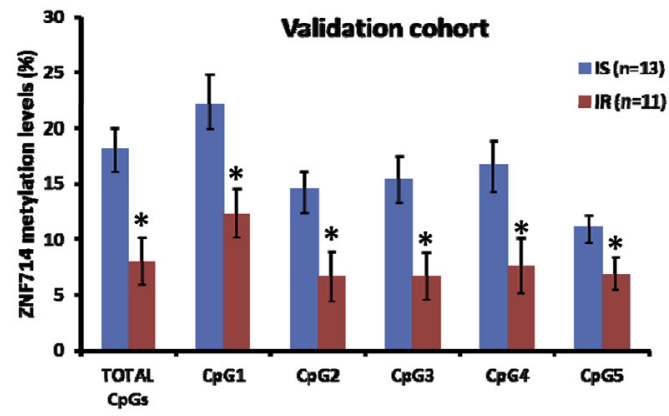

D

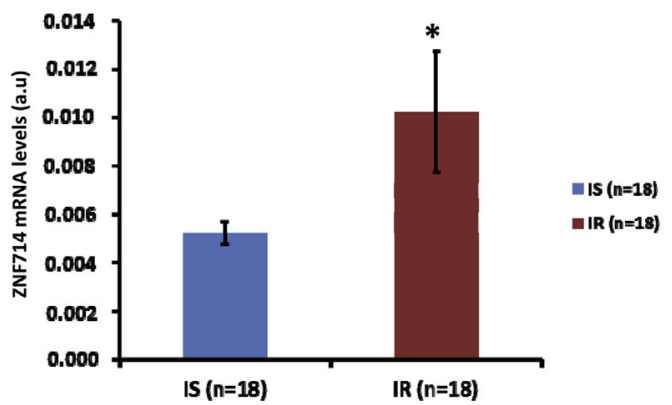

Fig 4. DNA methylation of ZNF714 is associated with a decrease in gene expression. (A) DNA methylation differences between IS and IR VAT samples from the discovery cohort measured by the $450 \mathrm{~K}$ array. (B) DNA methylation differences between IS and IR VAT samples measured by pyrosequencing from the discovery and (C) validation cohort. (D) Differential gene expression of ZNF714 between IS and IR VAT samples. IS, insulin sensitivity; IR, insulin resistance; VAT, visceral adipose tissue. *Denotes differences statistically significant $(P<0.05)$. reveals alterations in the methylation levels of collagenrelated genes such as COL9A1 and COL11A2 together with other genes included in the cell-adhesion category of functional processes, such as CD44, MUC4, and $A D A M 2$. In addition, the analysis identified relevant genes mapped by more than $2 \mathrm{CpG}$ sites that could play a crucial role in the development of IR induced by dysfunctional VAT, such as GATA4, TET1, ZNF714, $A D C Y 9, T B X 5$, and HDACM. Among these, the transcription factor GATA4 has been studied in the cardiac system to promote hypertrophy and mediate the leptininduced vascular, ${ }^{33}$ suggesting a putative role of this gene in hypertension associated with obesity. Moreover, it was discovered that the loss of intestinal GATA4 prevents diet-induced obesity, promotes insulin sensitivity, ${ }^{34}$ and protects against diet-induced hepatic steatosis ${ }^{34}$ in mice. TET1 is a demethylase that was shown to regulate epigenetically insulin-like growth factor 2 mRNA binding protein $1{ }^{35}$ TBX5 is a developmental gene that presented 4 DMCpGs. The gene was identified as a regulator of preadipocyte proliferation and adipogenic differentiation in abdominal adipose tissue under epigenetic control. ${ }^{36}$ The zinc finger protein 714 (ZNF714) exhibited the highest DNA methylation difference and was mapped by $5 \mathrm{DMCpGs}$ located in island/shore and promoter regions. The gene was found to present lower methylation levels in IR than in IS patients in association with increased transcription levels. Even though the functional association with the development of IR or T2D remains to be elucidated, future exploration of the role of this gene could reveal a novel mechanism involved in the development of IR and T2D in line with other zinc finger proteins, which are associated with adipogenesis, ${ }^{37,38} \mathrm{~T} 2 \mathrm{D}$, or insulin resistance. ${ }^{39,40}$

The strength of this study is that it was performed in a homogeneous population classified according to insulin sensitivity measured by the gold-standard technique for detecting dysregulation in insulin action. The relatively small sample size is a limitation of this study. Obtaining visceral adipose tissue from a homogeneous population of subjects in whom insulin action is measured using a euglycemic clamp remains a challenge. However, the statistical significance observed when using small populations typically indicates that there is a real difference between experimental groups. We decided to use $P$-values for differential methylation without correction for multiple testing because of the relatively small sample size. Therefore, the results should be interpreted cautiously. However, subsequent analyses were performed with highly stringent filters to gain consistent results, which were further validated in an independent cohort. Although the magnitude of the DNA 
methylation differences between groups could be considered small, these differences may have been observed because of the use of complex tissue instead of a single cell but also because the intergroup pathophysiological differences were within a narrow range of insulin action.

In conclusion, the present study demonstrates the existence of a specific methylome map associated with insulin resistance in VAT. This IR-related methylome exhibits a potential epigenetic regulation involved in the dysregulation of VAT that could predispose to insulin resistance and future T2D onset in morbidly obese patients. To the best of our knowledge, this study is the first to investigate the global methylome of VAT obtained from patients in the clinical setting of morbid obesity with and without insulin resistance. Further research based on the results obtained from this study will open new avenues for studying the role of VAT in driving insulin resistance and future T2D by identifying potential epigenetic biomarkers and novel therapeutic targets in the prevention and treatment of these metabolic disturbances.

\section{ACKNOWLEDGMENTS}

Conflicts of Interest: All authors have read the journal's policy on disclosure of potential conflicts of interest and have none to declare.

The authors thank Maria Amil and Maribel Rendo from Instituto de Investigacion Sanitaria de Santiago de Compostels (CHUS-IDIS), Spain, and Diana García and Carles Arribas from the Bellvitge Biomedical Research Institute (IDIBELL), Spain, for their technical support, as well as the Fatbank from the CIBER Fisiopatologia de la Obesidad y Nutricion (CIBERobn), Spain.

This work was supported by grants from the Fondo de Investigacion Sanitaria (FIS 2011/00214 and PI14/ 01012), and CIBER Fisiopatologia de la Obesidad y Nutricion (CIBERobn; CB06/003), Instituto de Salud Carlos III (ISCIII)-FEDER, Spanish Ministry of Health, Spain; the European Research Council (ERC) grant EPINORC (268626) and the Health and Science Departments of the Catalan Government (Generalitat de Catalunya), Spain. A.B. Crujeiras was funded by the ISCIII through a "Sara Borrell" research contract (C09/00365) and the Health Department of the Xunta the Galicia, Spain. A. Diaz-Lagares. was funded by the ISCIII through a "Río Hortega" research contract (CM14/00067). J. Sandoval is a "Miguel Servet" (MS13/00055) researcher. M. Esteller. is an ICREA Research Professor.

A.B. Crujeiras and A. Diaz-Lagares designed the experiments, analyzed the data, and wrote the manuscript. J. M. Moreno-Navarrete, J. Sandoval, D. Hervas, and A. Gomez analyzed the data. W. Ricart, F. F. Casanueva, and M. Esteller contributed to discussions and reviewed the manuscript. J. M. Fernandez-Real designed the experiments, contributed to discussions, and reviewed the manuscript. A.B. Crujeiras and J. M. Fernandez-Real are the guarantors of this work and, as such, had full access to all the data in the study and take responsibility for the integrity of the data and the accuracy of the data analysis. All authors have reviewed and approved the article and have read the journal's authorship agreement.

\section{SUPPLEMENTARY DATA}

Supplementary data related to this article can be found at http://dx.doi.org/10.1016/j.trsl.2016.07.002.

\section{REFERENCES}

1. Calori G, Lattuada G, Piemonti L, et al. Prevalence, metabolic features, and prognosis of metabolically healthy obese Italian individuals: the Cremona Study. Diabetes Care 2011;34:210-5.

2. Qiao Q, Gao W, Zhang L, Nyamdorj R, Tuomilehto J. Metabolic syndrome and cardiovascular disease. Ann Clin Biochem 2007; 44:232-63.

3. Reaven GM. Insulin resistance: the link between obesity and cardiovascular disease. Endocrinol Metab Clin North Am 2008;37: 581-601, vii-viii.

4. Arcidiacono B, Iiritano S, Nocera A, et al. Insulin resistance and cancer risk: an overview of the pathogenetic mechanisms. Exp Diabetes Res 2012;2012:789174.

5. Goodpaster BH, Thaete FL, Simoneau JA, Kelley DE. Subcutaneous abdominal fat and thigh muscle composition predict insulin sensitivity independently of visceral fat. Diabetes 1997;46: 1579-85.

6. Kelley DE, Thaete FL, Troost F, Huwe T, Goodpaster BH. Subdivisions of subcutaneous abdominal adipose tissue and insulin resistance. Am J Physiol Endocrinol Metab 2000;278:E941-8.

7. Bonora E, Del Prato S, Bonadonna RC, et al. Total body fat content and fat topography are associated differently with in vivo glucose metabolism in nonobese and obese nondiabetic women. Diabetes 1992;41:1151-9.

8. Zhang M, Hu T, Zhang S, Zhou L. Associations of different adipose tissue depots with insulin resistance: a systematic review and metaanalysis of observational studies. Sci Rep 2015;5:18495.

9. Lee MJ, Wu Y, Fried SK. Adipose tissue heterogeneity: implication of depot differences in adipose tissue for obesity complications. Mol Aspects Med 2013;34:1-11.

10. Elder SJ, Lichtenstein AH, Pittas AG, et al. Genetic and environmental influences on factors associated with cardiovascular disease and the metabolic syndrome. J Lipid Res 2009;50:1917-26.

11. Hamilton JP. Epigenetics: principles and practice. Dig Dis 2011; 29:130-5.

12. Portela A, Esteller M. Epigenetic modifications and human disease. Nat Biotechnol 2010;28:1057-68.

13. Crujeiras AB, Díaz-Lagares A. DNA methylation in obesity and associated diseases. In: Garcia-Gimenez J, ed. Epigenetic biomarkers and diagnostics. Valencia: Elsevier, 2016:313-29.

14. Dayeh T, Volkov P, Salo S, et al. Genome-wide DNA methylation analysis of human pancreatic islets from type 2 diabetic and nondiabetic donors identifies candidate genes that influence insulin secretion. PLoS Genet 2014;10:e1004160.

15. Keller M, Kralisch S, Rohde K, et al. Global DNA methylation levels in human adipose tissue are related to fat distribution and glucose homeostasis. Diabetologia 2014;57:2374-83. 
16. Guenard F, Tchernof A, Deshaies Y, et al. Differential methylation in visceral adipose tissue of obese men discordant for metabolic disturbances. Physiol Genomics 2014;46:216-22.

17. Jove M, Moreno-Navarrete JM, Pamplona R, Ricart W, PorteroOtin M, Fernandez-Real JM. Human omental and subcutaneous adipose tissue exhibit specific lipidomic signatures. Faseb J 2014;28:1071-81.

18. Bergman RN, Finegood DT, Ader M. Assessment of insulin sensitivity in vivo. Endocr Rev 1985;6:45-86.

19. Tam CS, Xie W, Johnson WD, Cefalu WT, Redman LM, Ravussin E. Defining insulin resistance from hyperinsulinemiceuglycemic clamps. Diabetes Care 2012;35:1605-10.

20. Sandoval J, Heyn H, Moran S, et al. Validation of a DNA methylation microarray for $450,000 \mathrm{CpG}$ sites in the human genome. Epigenetics 2011;6:692-702.

21. Heyn H, Carmona FJ, Gomez A, et al. DNA methylation profiling in breast cancer discordant identical twins identifies DOK7 as novel epigenetic biomarker. Carcinogenesis 2012;34:102-8.

22. Heyn H, Li N, Ferreira HJ, et al. Distinct DNA methylomes of newborns and centenarians. Proc Natl Acad Sci U S A 2012; 109:10522-7.

23. Falcon S, Gentleman R. Using GOstats to test gene lists for GO term association. Bioinformatics 2007;23:257-8.

24. Ronn T, Ling C. DNA methylation as a diagnostic and therapeutic target in the battle against type 2 diabetes. Epigenomics 2015;7: 451-60.

25. Volkmar M, Dedeurwaerder S, Cunha DA, et al. DNA methylation profiling identifies epigenetic dysregulation in pancreatic islets from type 2 diabetic patients. Embo J 2012;31:1405-26.

26. Nitert MD, Dayeh T, Volkov P, et al. Impact of an exercise intervention on DNA methylation in skeletal muscle from first-degree relatives of patients with type 2 diabetes. Diabetes 2012;61: 3322-32.

27. Nilsson E, Jansson PA, Perfilyev A, et al. Altered DNA methylation and differential expression of genes influencing metabolism and inflammation in adipose tissue from subjects with type 2 diabetes. Diabetes 2014;63:2962-76.

28. Ronn T, Volkov P, Davegardh C, et al. A six months exercise intervention influences the genome-wide DNA methylation pattern in human adipose tissue. PLoS Genet 2013;9:e1003572.
29. Arner P, Sinha I, Thorell A, Ryden M, Dahlman-Wright K, Dahlman I. The epigenetic signature of subcutaneous fat cells is linked to altered expression of genes implicated in lipid metabolism in obese women. Clin Epigenetics 2015;7:93.

30. Benton MC, Johnstone A, Eccles D, et al. An analysis of DNA methylation in human adipose tissue reveals differential modification of obesity genes before and after gastric bypass and weight loss. Genome Biol 2015;16:8.

31. Dahlman I, Sinha I, Gao H, et al. The fat cell epigenetic signature in post-obese women is characterized by global hypomethylation and differential DNA methylation of adipogenesis genes. Int J Obes (Lond) 2015;39:910-9.

32. Denis GV, Obin MS. 'Metabolically healthy obesity': origins and implications. Mol Aspects Med 2013;34:59-70.

33. Ghantous CM, Kobeissy FH, Soudani N, et al. Mechanical stretch-induced vascular hypertrophy occurs through modulation of leptin synthesis-mediated ROS formation and GATA-4 nuclear translocation. Front Pharmacol 2015;6:240.

34. Patankar JV, Obrowsky S, Doddapattar P, et al. Intestinal GATA4 deficiency protects from diet-induced hepatic steatosis. J Hepatol 2012;57:1061-8.

35. Mahaira LG, Katsara O, Pappou E, et al. IGF2BP1 expression in human mesenchymal stem cells significantly affects their proliferation and is under the epigenetic control of TET1/2 demethylases. Stem Cells Dev 2014:23:2501-12.

36. Pinnick KE, Nicholson G, Manolopoulos KN, et al. Distinct developmental profile of lower-body adipose tissue defines resistance against obesity-associated metabolic complications. Diabetes 2014;63:3785-97.

37. Kang S, Akerblad P, Kiviranta R, et al. Regulation of early adipose commitment by Zfp521. PLoS Biol 2012;10:e1001433.

38. Gupta RK, Arany Z, Seale P, et al. Transcriptional control of preadipocyte determination by Zfp423. Nature 2010;464:619-23.

39. Jia Y, Yuan L, Hu W, et al. Zinc-finger BED domain-containing 3 (Zbed3) is a novel secreted protein associated with insulin resistance in humans. J Intern Med 2014;275:522-33.

40. Scherneck S, Vogel H, Nestler M, Kluge R, Schurmann A, Joost HG. Role of zinc finger transcription factor zfp69 in body fat storage and diabetes susceptibility of mice. Results Probl Cell Differ 2010;52:57-68. 


\section{APPENDIX}

\section{SUPPLEMENTARY METHODS}

DNA preparation and bisulfite conversion. DNA from fresh-frozen (FF) tissue samples was isolated using a standard phenol-chloroform/proteinase-k protocol. After proteinase- $\mathrm{K}$ incubation, adipose tissue homogenates were centrifuged $\left(13000 \mathrm{~g}, 2^{\circ} \mathrm{C}, 30 \mathrm{~min}\right)$ to avoid lipid interference in the DNA purification process. The obtained DNA was treated with RNase A for 1 hour at $45^{\circ} \mathrm{C}$. All DNA samples were quantified using the fluorometric method (Quan-iT PicoGreen DsDNA Assay, Life Technologies) and were assessed for purity using a NanoDrop (Thermo Scientific) with 260/280 and 260/230 ratio measurements. The integrity of the FF DNA was verified by electrophoresis in $1.3 \%$ agarose gel. FF DNA (600 ng) was processed using the EZ-96 DNA Methylation kit (Zymo Research Corp.) following the manufacturer's recommendations for Infinium assays.

\section{DNA methylation analysis.}

Infinium Human Methylation 450 BeadChip array. Microarray-based DNA methylation analysis was conducted with the Infinium Human Methylation 450 BeadChip (450K array). DNA quality checks, bisulfite modification, hybridization, data normalization, statistical filtering, and $\beta$ value calculations were performed as described elsewhere. ${ }^{20}$ High-quality DNA samples obtained from subcutaneous adipose tissue and leukocytes were selected for bisulfite conversion (Zymo Research; EZ-96 DNA Methylation Kit) and hybridization to the Infinium Human Methylation 450 BeadChips (Illumina) following the Illumina Infinium HD methylation protocol. The DNA concentration of the quality-control sample standards was measured using the PicoGreen method (Invitrogen) coupled with assessments of DNA purity based on the A260/A280 ratio (ranging between 1.75 and 1.95) and the A260/A230 ratio (ranging between 2.00 and 2.20). Analysis with $1 \%$ agarose gel electrophoresis allowed for the exclusion of samples with possible DNA fragmentation or RNA contamination. The Infinium Human Methylation 450 BeadChip provides coverage of $>450,000 \mathrm{CpG}$ sites targeting nearly all of the RefSeq genes $(>99 \%) .{ }^{20}$ The chips were designed to cover the coding and noncoding genes without bias against those lacking $\mathrm{CpG}$ islands. The design further aimed to cover not only promoter regulatory regions but also $\mathrm{CpGs}$ across gene regions to include the $5^{\prime}$-untranslated regions, the first exons, the gene bodies, and the $3^{\prime}$-untranslated regions.

In total, $600 \mathrm{ng}$ from the high-quality DNA samples was bisulfite converted. Whole-genome amplification and hybridization were then performed on the BeadChip and followed by single-base extension and analysis on a HiScan SQ module (Illumina) to assess the cytosine methylation states. The annotation of the $\mathrm{CpG}$ islands (CGI) involved the following categorization ${ }^{1}$ : shore, for each of the 2-Kb sequences flanking a $\mathrm{CGI}^{2}$; shelf, for each of the 2-kb sequences next to a shore; and ${ }^{3}$ open sea, for DNA not included in any of the previous sequences or in CGIs. ${ }^{21}$ The transcription start site 200 and the transcription start site 1500 indicate the regions either 200 or $1500 \mathrm{bp}$ from the transcription start site, respectively.

Pyrosequencing analysis. Pyrosequencing was used to assess selected markers as previously described. ${ }^{22}$ The primer sequences used in this analysis were designed using Qiagen's PyroMark Assay Design 2.0 software to hybridize to CpG-free sites to ensure methylation-independent amplification. Briefly, polymerase chain reaction (PCR) was performed using standard conditions with biotinylated primers, and the PyroMark Vacuum Prep Tool (Biotage, Uppsala, Sweden) was used to prepare single-stranded PCR products according to the manufacturer's instructions. Pyrosequencing reactions and methylation quantification were performed in a PyroMark Q96 System version 2.0.6 (Qiagen), using appropriate reagents and recommended protocols. The primer sequences used were (all given $5^{\prime}>$ '3): ZNF714 prePCR fwd: [Btn]GGAAGTTTAGAAATGGTGAGAGT, ZNF714 pre-PCR reverse: CCCCTAAAАCCCTCCAATAATC, ZNF714 seq: AATCCCTACACAATCC.

Gene expression analyses. Briefly, RNA purification was performed using the RNeasy Lipid Tissue Mini Kit (Qiagen, Izasa SA, Barcelona, Spain), and the integrity was verified using an Agilent Bioanalyzer (Agilent Technologies, Palo Alto, Calif). Gene expression was assessed by real-time PCR using TaqMan technology suitable for relative genetic-expression quantification in a LightCycler 480 Real-Time PCR System (Roche Diagnostics SL, Barcelona, Spain). The RT-PCR reaction was performed in a final volume of $12 \mu \mathrm{l}$. The cycle program consisted of an initial denaturing of 10 minutes at $95^{\circ} \mathrm{C}$ and then 40 cycles of 15 seconds denaturizing phase at $95^{\circ} \mathrm{C}$ and a 1 minute annealing and extension phase at $60^{\circ} \mathrm{C}$. A threshold cycle $(\mathrm{Ct}$ value) was obtained for each amplification curve, and a $\Delta \mathrm{Ct}$ value was first calculated by subtracting the $\mathrm{Ct}$ value for human peptidylprolyl isomerase A (cyclophilin A; PPIA) RNA from the Ct value for each sample. Fold changes relative to the endogenous control were then determined by calculating $2-\Delta \mathrm{Ct}$; therefore, geneexpression results are expressed as the expression ratio 
relative to PPIA gene expression according to the manufacturers' guidelines. The commercially available and prevalidated TaqMan primer/probe sets used were as follows: PPIA (4333763, endogenous control) and zinc finger protein 714 (ZNF714, Hs02743732_s1; Life Technologies S.A., Madrid, Spain).
A

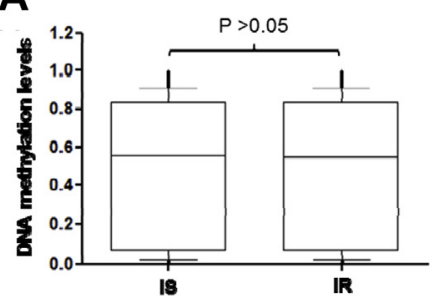

D
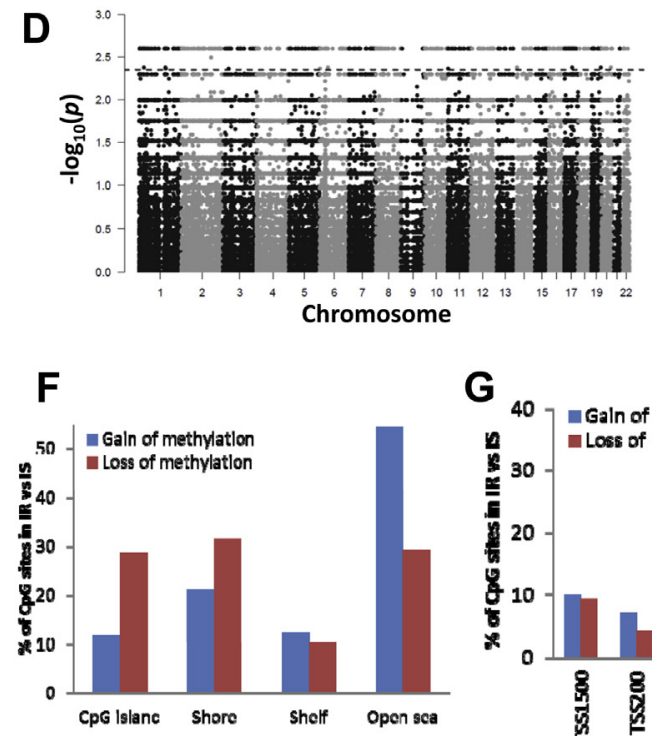

G
B

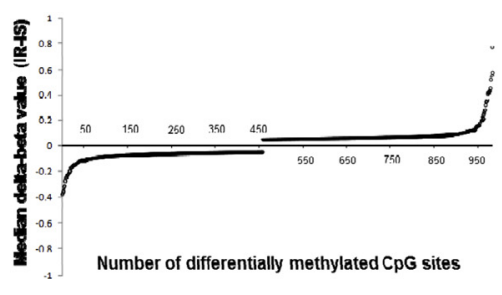

C

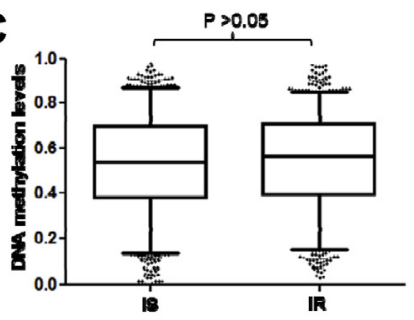

\section{E}

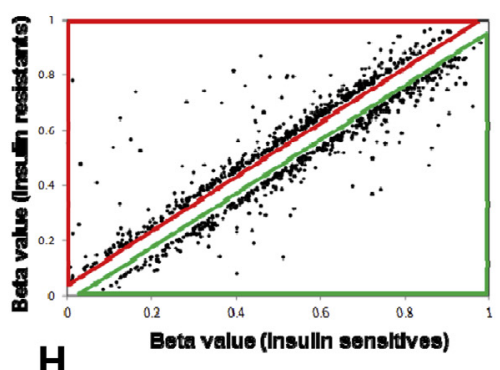

$\mathbf{H}$
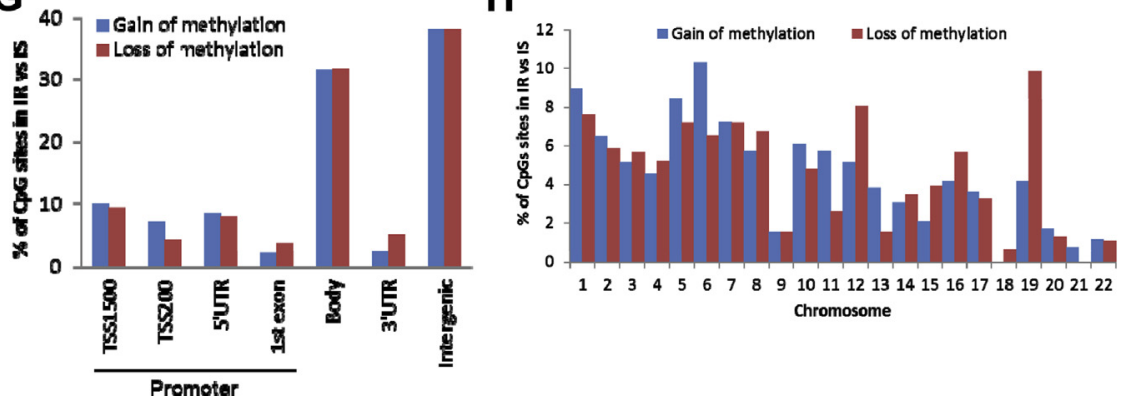

Supplementary Fig 1. (A) Differences in the global average methylation levels of the overall valid CpGs between the insulin-resistant (IR) and insulin-sensitivity (IS) samples. (B) Range of differences between IR and IS samples among the differentially methylated $\mathrm{CpG}$ sites. (C) Global differences in the methylation levels of the differentially methylated $\mathrm{CpGs}$ identified by the $450 \mathrm{~K}$ array analysis. (D) Manhattan plot showing epigenome-wide $P$ values of association. The $y$ axis shows the $-\log _{10}(p)$ values of 447,104 valid CpGs, and the $x$ axis shows their chromosomal position. The horizontal discontinuous line represents the threshold of $P<.05$ for selecting differentially methylated $\mathrm{CpG}$ sites. (E). Correlation of the methylation levels between a representative sample of IR and IS. (F-H). Genomic distributions of the differentially methylated CpG sites comparing those that exhibited an increase with those that exhibited a decrease in methylation levels and their respective locations in the broader $\mathrm{CpG}$ context, the gene region, and chromosome distribution, respectively. 
Supplementary Table II. Differentially DNA methylated CpGS (DMCPGs) of diabetes-associated genes according to the Human Diabetes Proteome Project (HDPP)

\begin{tabular}{|c|c|c|c|c|c|c|c|c|c|c|}
\hline TargetID & CHR & Gene name & CpG context & Gene region & $\begin{array}{l}\text { IS } \\
\text { methylation } \\
\text { levels } \\
\text { (mean) }\end{array}$ & $\begin{array}{c}\text { IS } \\
\text { methylation } \\
\text { levels (SD) }\end{array}$ & $\begin{array}{l}\text { IR group } \\
\text { methylation } \\
\text { levels } \\
\text { (mean) }\end{array}$ & $\begin{array}{l}\text { IR group } \\
\text { methylation } \\
\text { levels (SD) }\end{array}$ & $\begin{array}{c}\text { Differences } \\
\text { (IR-IS) }\end{array}$ & $\begin{array}{c}P . \\
\text { value }\end{array}$ \\
\hline cg08764927 & 1 & PER3; PER3 & Island & 5'UTR; 1stExon & 0.64 & 0.04 & 0.58 & 0.05 & -0.06 & 0.048 \\
\hline $\operatorname{cg} 13457410$ & 1 & PIK3CD & & 5'UTR & 0.13 & 0.04 & 0.22 & 0.06 & 0.09 & 0.018 \\
\hline cg22367705 & 1 & SLC9A1 & Island & TSS200 & 0.04 & 0.01 & 0.10 & 0.13 & 0.07 & 0.005 \\
\hline cg19693031 & 1 & TXNIP & & 3'UTR & 0.51 & 0.04 & 0.44 & 0.05 & -0.06 & 0.048 \\
\hline cg11723801 & 1 & NES & Island & 1stExon & 0.10 & 0.03 & 0.15 & 0.04 & 0.05 & 0.030 \\
\hline cg09470983 & 3 & TFRC; TFRC & N_Shelf & 5'UTR; 5'UTR & 0.74 & 0.06 & 0.67 & 0.03 & -0.07 & 0.018 \\
\hline cg00398048 & 4 & AGA & S_Shore & TSS1500 & 0.31 & 0.07 & 0.23 & 0.05 & -0.08 & 0.030 \\
\hline cg23210478 & 5 & EBF1 & & Body & 0.41 & 0.06 & 0.50 & 0.04 & 0.08 & 0.030 \\
\hline cg10784548 & 5 & NSD1; NSD1 & & Body; body & 0.53 & 0.05 & 0.46 & 0.07 & -0.07 & 0.048 \\
\hline cg05554718 & 6 & HIST1H1D & & TSS1500 & 0.73 & 0.02 & 0.56 & 0.26 & -0.17 & 0.030 \\
\hline cg17977304 & 6 & $\begin{array}{l}\text { MOG; MOG; MOG; MOG; } \\
\text { MOG; MOG; MOG; MOG; } \\
\text { MOG; MOG; MOG }\end{array}$ & & $\begin{array}{c}\text { TSS1500; TSS1500; } \\
\text { TSS1500; TSS1500; } \\
\text { TSS1500; TSS1500; } \\
\text { TSS1500; TSS1500; } \\
\text { TSS1500; TSS1500; } \\
\text { TSS1500 }\end{array}$ & 0.30 & 0.03 & 0.37 & 0.06 & 0.06 & 0.048 \\
\hline cg07858113 & 6 & IER3; FLOT1 & Island & 3'UTR; TSS1500 & 0.23 & 0.07 & 0.15 & 0.03 & -0.08 & 0.048 \\
\hline cg20549346 & 6 & C6orf10 & & Body & 0.32 & 0.35 & 0.74 & 0.03 & 0.42 & 0.003 \\
\hline cg08265274 & 6 & HLA-DRB5 & S_Shore & Body & 0.40 & 0.11 & 0.23 & 0.12 & -0.17 & 0.030 \\
\hline cg07984380 & 6 & HLA-DRB1 & & Body & 0.03 & 0.00 & 0.26 & 0.20 & 0.24 & 0.030 \\
\hline cg13910785 & 6 & HLA-DRB1 & N_Shelf & Body & 0.01 & 0.02 & 0.23 & 0.33 & 0.22 & 0.034 \\
\hline cg19575208 & 6 & HLA-DRB1 & Island & Body & 0.46 & 0.10 & 0.30 & 0.11 & -0.16 & 0.018 \\
\hline cg08845336 & 6 & HLA-DRB1 & Island & Body & 0.47 & 0.15 & 0.30 & 0.11 & -0.17 & 0.030 \\
\hline cg08231637 & 6 & HLA-DRB1 & & Body & 0.03 & 0.06 & 0.48 & 0.30 & 0.45 & 0.039 \\
\hline cg10385522 & 6 & HLA-DRB1 & & TSS1500 & 0.00 & 0.00 & 0.55 & 0.45 & 0.55 & 0.012 \\
\hline cg14799809 & 6 & HLA-DQA1 & & Body & 0.39 & 0.46 & 0.82 & 0.22 & 0.42 & 0.048 \\
\hline cg03638120 & 6 & HLA-DQB2 & Island & Body & 0.36 & 0.04 & 0.41 & 0.04 & 0.05 & 0.030 \\
\hline cg18599231 & 6 & HLA-DOB & & TSS1500 & 0.54 & 0.01 & 0.47 & 0.04 & -0.06 & 0.003 \\
\hline cg08327277 & 6 & TAP2; TAP2 & & 3'UTR; body & 0.79 & 0.03 & 0.73 & 0.04 & -0.05 & 0.018 \\
\hline cg25283336 & 6 & HLA-DPA1 & & 3'UTR & 0.92 & 0.01 & 0.83 & 0.10 & -0.09 & 0.010 \\
\hline cg13726184 & 6 & IGF2R & S_Shelf & Body & 0.59 & 0.05 & 0.65 & 0.03 & 0.06 & 0.010 \\
\hline cg23347850 & 7 & ICA1; ICA1; ICA1 & & 5'UTR; 5'UTR; 5'UTR & 0.51 & 0.04 & 0.57 & 0.04 & 0.06 & 0.048 \\
\hline cg00917413 & 7 & CAV2; CAV2 & N_Shore & TSS1500; TSS1500 & 0.72 & 0.03 & 0.78 & 0.06 & 0.05 & 0.048 \\
\hline cg07571734 & 7 & PRKAG2; PRKAG2 & N_Shore & Body; body & 0.23 & 0.02 & 0.17 & 0.04 & -0.06 & 0.010 \\
\hline cg02860921 & 7 & PTPRN2; PTPRN2; PTPRN2 & S_Shelf & Body; body; body & 0.69 & 0.01 & 0.75 & 0.03 & 0.06 & 0.005 \\
\hline $\operatorname{cg} 11468861$ & 7 & PTPRN2; PTPRN2; PTPRN2 & & Body; body; body & 0.44 & 0.04 & 0.51 & 0.06 & 0.06 & 0.048 \\
\hline cg15727524 & 7 & PTPRN2; PTPRN2; PTPRN2 & & Body; body; body & 0.27 & 0.02 & 0.32 & 0.03 & 0.05 & 0.018 \\
\hline cg15807855 & 7 & PTPRN2; PTPRN2; PTPRN2 & & Body; body; body & 0.50 & 0.02 & 0.55 & 0.03 & 0.06 & 0.003 \\
\hline & & & & & & & & & \multicolumn{2}{|c|}{ (Continued) } \\
\hline
\end{tabular}




\begin{tabular}{|c|c|c|c|c|c|c|c|c|c|c|}
\hline TargetID & $\mathrm{CHR}$ & Gene name & CpG context & Gene region & $\begin{array}{c}\text { IS } \\
\text { methylation } \\
\text { levels } \\
\text { (mean) }\end{array}$ & $\begin{array}{c}\text { IS } \\
\text { methylation } \\
\text { levels (SD) }\end{array}$ & $\begin{array}{l}\text { IR group } \\
\text { methylation } \\
\text { levels } \\
\text { (mean) }\end{array}$ & $\begin{array}{l}\text { IR group } \\
\text { methylation } \\
\text { levels (SD) }\end{array}$ & $\begin{array}{l}\text { Differences } \\
\quad(I R-I S)\end{array}$ & $\begin{array}{c}P . \\
\text { value }\end{array}$ \\
\hline cg11062158 & 7 & PTPRN2; PTPRN2; PTPRN2 & N_Shore & Body; body; body & 0.98 & 0.01 & 0.92 & 0.04 & -0.06 & 0.010 \\
\hline cg06152586 & 7 & PTPRN2; PTPRN2; PTPRN2 & Island & Body; body; body & 0.82 & 0.07 & 0.69 & 0.09 & -0.14 & 0.048 \\
\hline cg00369194 & 7 & PTPRN2; PTPRN2; PTPRN2 & N_Shore & Body; body; body & 0.71 & 0.05 & 0.61 & 0.06 & -0.09 & 0.018 \\
\hline cg09409457 & 7 & PTPRN2; PTPRN2; PTPRN2 & N_Shelf & Body; body; body & 0.71 & 0.05 & 0.77 & 0.04 & 0.06 & 0.030 \\
\hline cg23602909 & 7 & PTPRN2; PTPRN2; PTPRN2 & N_Shore & Body; body; body & 0.71 & 0.03 & 0.77 & 0.05 & 0.06 & 0.048 \\
\hline cg08955548 & 7 & PTPRN2; PTPRN2; PTPRN2 & N_Shore & Body; body; body & 0.65 & 0.05 & 0.77 & 0.09 & 0.11 & 0.048 \\
\hline cg27194152 & 7 & PTPRN2; PTPRN2; PTPRN2 & S_Shore & Body; body; body & 0.91 & 0.02 & 0.86 & 0.04 & -0.05 & 0.048 \\
\hline cg20528787 & 7 & PTPRN2; PTPRN2; PTPRN2 & & Body; body; body & 0.49 & 0.08 & 0.39 & 0.07 & -0.10 & 0.030 \\
\hline cg02770061 & 7 & PTPRN2; PTPRN2; PTPRN2 & & Body; body; body & 0.81 & 0.06 & 0.73 & 0.05 & -0.07 & 0.018 \\
\hline cg12834378 & 7 & PTPRN2; PTPRN2; PTPRN2 & & Body; body; body & 0.76 & 0.05 & 0.67 & 0.03 & -0.09 & 0.010 \\
\hline cg10993470 & 8 & RP1 & Island & Body & 0.90 & 0.05 & 0.96 & 0.02 & 0.06 & 0.048 \\
\hline cg24222992 & 10 & CAMK1D; CAMK1D & & Body; body & 0.78 & 0.03 & 0.83 & 0.03 & 0.05 & 0.018 \\
\hline cg02928885 & 10 & GAD2; GAD2 & & Body; body & 0.53 & 0.04 & 0.59 & 0.03 & 0.07 & 0.005 \\
\hline cg10031769 & 10 & $\begin{array}{c}\text { CREM; CREM; CREM; } \\
\text { CREM; CREM; CREM; } \\
\text { CREM; CREM; CREM; } \\
\text { CREM; CREM; CREM; } \\
\text { CREM; CREM; } \\
\text { CREM; CREM; } \\
\text { CREM; CREM; } \\
\text { CREM; CREM }\end{array}$ & & $\begin{array}{c}\text { Body; body; body; } \\
\text { body; TSS200; } \\
\text { 5'UTR; } \\
\text { TSS200; TSS1500; } \\
\text { body; TSS1500; } \\
\text { TSS1500; } \\
\text { TSS1500; 5'UTR; } \\
\text { body; body; } \\
\text { TSS1500; } \\
\text { TSS200; body; body; } \\
\text { TSS200 }\end{array}$ & 0.75 & 0.02 & 0.69 & 0.05 & -0.06 & 0.048 \\
\hline cg07001963 & 10 & CXCL12; CXCL12; CXCL12 & N_Shore & Body; body; body & 0.22 & 0.04 & 0.27 & 0.05 & 0.05 & 0.048 \\
\hline cg16490176 & 10 & PLAU; C10orf55; PLAU & Island & $\begin{array}{c}\text { TSS200; 3'UTR; } \\
\text { TSS200 }\end{array}$ & 0.30 & 0.02 & 0.25 & 0.03 & -0.05 & 0.010 \\
\hline cg16490176 & 10 & PLAU; C10orf55; PLAU & Island & $\begin{array}{c}\text { TSS200; 3'UTR; } \\
\text { TSS200 }\end{array}$ & 0.30 & 0.02 & 0.25 & 0.03 & -0.05 & 0.010 \\
\hline cg08604416 & 10 & SORBS1; SORBS1 & & 5'UTR; 5'UTR & 0.62 & 0.03 & 0.68 & 0.03 & 0.06 & 0.018 \\
\hline cg03440556 & 10 & SCD & S_Shore & Body & 0.32 & 0.04 & 0.40 & 0.06 & 0.08 & 0.030 \\
\hline cg16106427 & 10 & STK32C & S_Shelf & Body & 0.88 & 0.02 & 0.82 & 0.04 & -0.05 & 0.030 \\
\hline cg02114346 & 10 & PAOX; PAOX; PAOX & N_Shore & $\begin{array}{c}\text { TSS1500; TSS1500; } \\
\text { TSS1500 }\end{array}$ & 0.61 & 0.03 & 0.55 & 0.03 & -0.06 & 0.010 \\
\hline cg14593191 & 11 & $\begin{array}{c}\text { CD44; CD44; CD44; } \\
\text { CD44; CD44 }\end{array}$ & & $\begin{array}{l}\text { Body; body; body; } \\
\text { body; body }\end{array}$ & 0.37 & 0.02 & 0.44 & 0.02 & 0.06 & 0.003 \\
\hline cg08133496 & 11 & EXT2; EXT2 & N_Shore & TSS200; TSS200 & 0.33 & 0.03 & 0.39 & 0.03 & 0.06 & 0.009 \\
\hline cg04827223 & 11 & ARAP1 & N_Shore & Body & 0.80 & 0.03 & 0.75 & 0.03 & -0.06 & 0.010 \\
\hline cg09558982 & 11 & APOA1 & S_Shore & TSS200 & 0.35 & 0.07 & 0.45 & 0.09 & 0.11 & 0.048 \\
\hline cg12823408 & 11 & ARHGEF12 & & 3'UTR & 0.74 & 0.18 & 0.84 & 0.02 & 0.10 & 0.048 \\
\hline
\end{tabular}




\begin{tabular}{|c|c|c|c|c|c|c|c|c|c|c|}
\hline cg15381313 & 12 & $\mathrm{NR} 1 \mathrm{H} 4$ & & TSS200 & 0.49 & 0.05 & 0.56 & 0.04 & 0.07 & 0.018 \\
\hline cg18874332 & 12 & $\mathrm{NR} 1 \mathrm{H} 4$ & & TSS200 & 0.22 & 0.04 & 0.28 & 0.05 & 0.06 & 0.030 \\
\hline cg03771004 & 12 & $\mathrm{NR} 1 \mathrm{H} 4 ; \mathrm{NR} 1 \mathrm{H} 4$ & & 5'UTR; 1stExon & 0.64 & 0.03 & 0.70 & 0.03 & 0.06 & 0.010 \\
\hline cg07472750 & 13 & HMGB1 & & 5'UTR & 0.00 & 0.01 & 0.06 & 0.04 & 0.05 & 0.033 \\
\hline cg17878506 & 13 & TBC1D4 & Island & TSS1500 & 0.13 & 0.10 & 0.25 & 0.11 & 0.12 & 0.048 \\
\hline cg16421871 & 13 & MCF2L; MCF2L & N_Shore & Body; body & 0.34 & 0.06 & 0.25 & 0.05 & -0.08 & 0.048 \\
\hline cg05008070 & 14 & DACT1; DACT1 & S_Shore & Body; body & 0.54 & 0.06 & 0.61 & 0.04 & 0.06 & 0.048 \\
\hline cg07470694 & 15 & ATP10A & S_Shore & TSS1500 & 0.73 & 0.07 & 0.81 & 0.03 & 0.08 & 0.030 \\
\hline cg01512138 & 16 & CLEC16A & & Body & 0.56 & 0.04 & 0.61 & 0.04 & 0.05 & 0.048 \\
\hline cg27457921 & 17 & $\begin{array}{c}\text { МАPT; MAPT; MAPT; } \\
\text { МАPT; MAPT; MAPT }\end{array}$ & S_Shore & $\begin{array}{l}\text { 5'UTR; 5'UTR; 5'UTR; } \\
\text { 5'UTR; 5'UTR; 5'UTR }\end{array}$ & 0.72 & 0.03 & 0.66 & 0.04 & -0.06 & 0.030 \\
\hline cg03077331 & 17 & FN3K & Island & TSS1500 & 0.07 & 0.03 & 0.13 & 0.03 & 0.06 & 0.018 \\
\hline cg26446133 & 18 & CNDP2; CNDP2; CNDP2 & S_Shelf & 5'UTR; 1stExon; 5'UTR & 0.68 & 0.07 & 0.40 & 0.26 & -0.28 & 0.048 \\
\hline cg21586152 & 19 & ELANE & N_Shore & Body & 0.61 & 0.04 & 0.54 & 0.05 & -0.07 & 0.048 \\
\hline $\operatorname{cg} 15104526$ & 19 & INSL3 & Island & TSS200 & 0.87 & 0.03 & 0.93 & 0.04 & 0.06 & 0.030 \\
\hline cg24292351 & 19 & INSL3 & Island & TSS200 & 0.88 & 0.03 & 0.93 & 0.04 & 0.05 & 0.030 \\
\hline $\operatorname{cg} 14061069$ & 19 & $\begin{array}{l}\text { DMPK; DMPK; } \\
\text { DMPK; DMPK }\end{array}$ & Island & Body; body; body; body & 0.40 & 0.04 & 0.32 & 0.06 & -0.07 & 0.030 \\
\hline cg03529184 & 20 & DEFB124; REM1 & N_Shore & TSS1500; TSS1500 & 0.52 & 0.05 & 0.59 & 0.03 & 0.07 & 0.030 \\
\hline cg23303369 & 20 & MMP9 & Island & Body & 0.33 & 0.05 & 0.39 & 0.03 & 0.06 & 0.048 \\
\hline cg23484981 & 20 & $\begin{array}{l}\text { GNAS; GNAS; } \\
\text { GNAS; GNASAS }\end{array}$ & N_Shore & $\begin{array}{r}\text { TSS1500; TSS1500; } \\
\text { 3'UTR; TSS1500 }\end{array}$ & 0.56 & 0.18 & 0.46 & 0.02 & -0.10 & 0.018 \\
\hline cg17505852 & 22 & $\begin{array}{c}\text { NF2; NF2; NF2; NF2; NF2; } \\
\text { NF2; NF2; NF2; NF2 }\end{array}$ & S_Shelf & $\begin{array}{l}\text { Body; body; body; } \\
\text { body; body; } \\
\text { body; body; } \\
\text { Body; body }\end{array}$ & 0.57 & 0.05 & 0.63 & 0.02 & 0.06 & 0.030 \\
\hline
\end{tabular}

Abbreviations: IS, insulin sensitive patients; IR, insulin resistant patients; $S D$, standard deviation. 